\title{
ANTICLERICALISMO Y PODER: LA DESACRALIZACIÓN DE LAS CALLES Y LOS ESPACIOS PÚBLICOS DURANTE LA SEGUNDA REPÚBLICA
}

\author{
POR \\ ANTONIO MANUEL MORAL RONCAL \\ Departamento de Historia II, Facultad de Filosofia y Letras, Universidad de Alcalá
}

\begin{abstract}
RESUMEN: Entre 1931 y 1939, la política laicista republicana intentó suprimir los recursos espaciales de santificación incluso en el callejero urbano, ya que resultaba ser un proceso de acuartelamiento de lo sagrado que facilitaba la exención de aquella obediencia hasta entonces debida a los principios que la religión vehiculaba a través de sus ritos y manifestaciones omnipresentes. Estas medidas adoptaron un contenido anticlerical evidente.
\end{abstract}

PALABRAS CLAVE: Segunda República, política laicista, anticlericalismo, espacios públicos.

\section{ANTICLERICALISM AND POWER: DESACRALIZACIÓN OF THE STREETS AND THE PUBLIC SPACES DURING THE SECOND REPUBLIC}

\begin{abstract}
Between 1931 and 1939, the republican laicize political tried to even suppress the space resources of sanctification in the street one urban, since it turned out to be a process of quartering of the sacred thing that facilitated the excuse of that obedience until then due to the principles that the religion making through its rites and omnipresent manifestations. These measures adopted an anticlerical evident content.
\end{abstract}

KEYWORDS: Second Republic, laicize political, anticlericalism, public spaces.

Recibido/Received 2011-10-07

Aceptado/Accepted 2011-11-25

\section{EL ACUARTELAMIENTO DE LO SAGRADO COMO OBJETIVO SECULARIZADOR}

Durante la Segunda República, la conjunción republicano-socialista trató de mermar o destruir totalmente las manifestaciones rituales católicas en la vida pública, en la calle, al aire libre, recluyendo de esa manera simbólicamente la religión al interior de las casas, al interior de la vida de cada ser humano. ${ }^{1}$ La política laicista republicana debía suprimir los recursos espaciales de santificación que organizaban los ciclos y los episodios de la vida comunitaria de los españoles, ya que resultaba ser un

\footnotetext{
${ }^{1}$ Este artículo forma parte del proyecto de investigación Catolicismo y laicismo en la España de entreguerras, 1919-1939, número de referencia HAR2008-02405/HIST. Agradezco las indicaciones del doctor Joseba Louzao (Universidad del País Vasco).
} 
proceso de acuartelamiento de lo sagrado, que facilitaba la exención de aquella obediencia hasta entonces debida a los principios que la religión vehiculaba a través de sus ritos y manifestaciones omnipresentes. Desde abril de 1931, los nuevos dirigentes políticos trataron de romper la identificación comunidad-religión (España-catolicismo), tratando de construir, desde los medios que les proporcionaba su conquista del aparato estatal, un nuevo concepto de nación y sociedad españolas. ${ }^{2}$ Los campos de confrontación de este proyecto con la comunidad católica fueron muy variados: desde la concepción del Estado y de la identidad nacional hasta la educación y la vida social. ${ }^{3}$

La calle, el espacio público, también se convirtió en objeto preferente de confrontación y conquista, ya que no sólo era un telón, un decorado o un marco social, sino un activo agente cultural, ámbito de acción de dispositivos que prescribían y acomodaban lo que acontecía en la sociedad, a los que ésta se podía plegar expeditamente. Si bien los ciudadanos organizaban el espacio urbano, a su vez éste les sometía, por lo que se convirtió en un importante punto de litigo en el conflicto laicizador de los años treinta en España. ${ }^{4}$ Desde hacía varias décadas, los anticlericales deseaban la destrucción de los mecanismos espaciales directamente comprometidos en tareas de territorialización, principio aplicable a edificios, cruces, imágenes... que conformaban, ayudaban a definir y sacramentalizaban el espacio social. Esa tarea se podía realizar por medio de acciones violentas o de una serie de rotundas medidas legislativas, a nivel nacional o municipal. Los elementos que se convirtieron en su objetivo habían jerarquizado el espacio, zonificándolo a la vez religiosa y socialmente, asignando sobre el mismo, como una red invisible, una serie constituida de contrastes y complementariedades, levantando fronteras, construyendo puentes simbólicos, bajo la justificación de la fe. En cuanto se constituyeron las primeras autoridades municipales republicanas, entre el 12 y el 14 de abril de 1931, comenzaron las medidas de desactivación de los elementos del paisaje considerados incompatibles con un proyecto civilizador y modernizador en construcción. En Málaga, el 1 de mayo, fue descubierta una lápida con el nombre de Pablo Iglesias, que bautizaba a la Alameda principal, la gran vía burguesa, para los proletarios. Como sintió un espectador de los hechos, "no era vana ilusión, el nombre del apóstol de socialismo lo certificaba, la ciudad les pertenecía". "Lo mismo ocurrió en las celebraciones de Eibar donde el paseo de San Andrés recibió el nombre del líder socialista. Los lugares y elementos a destruir fueron interpretados como focos y símbolos desde los cuales actuaban -superando los factores económicos y políticos- los niveles más profundos y determinantes de una cosmovisión religiosa, todavía hegemónica, que debía eliminarse para lograr una nación nueva y perfeccionada. Resulta pues,

${ }^{2}$ Un resumen de la dinámica secularizadora y anticlerical en Moral Roncal A.M. 2009. La cuestión religiosa en la Segunda República. Iglesia y carlismo: 13-28 Madrid: Biblioteca Nueva.

${ }^{3}$ Se intentó llevar la revolución republicana a las conciencias de los españoles, como han señalado algunos historiadores como Álvarez tardio, M. 2002. Anticlericalismo y libertad de conciencia: Madrid: CEPC; Arbeloa, V. M. 2008. "Iglesia y Segunda República española", en Bullón de Mendoza, A. y Togores, L. (Coords.). La República y la Guerra Civil setenta años después: 306-315 Madrid: Actas. Sobre la situación del catolicismo en vísperas del régimen republicano resultan sugerentes los enfoques de Cano, L. 2009. Reinaré en España. La mentalidad católica a la llegada de la Segunda República: Madrid: Biblioteca Nueva, y Requena, F. M. 2009. Católicos, devociones y sociedad durante la dictadura de Primo de Rivera y la Segunda República: Madrid: Biblioteca Nueva.

${ }^{4}$ De ahí que, para algunos historiadores, la lógica anticlerical fue, en este sentido, una lógica topográfica. Ver Delgado Ruiz, M. 1997."Anticlericalismo, espacio y poder. La destrucción de los rituales católicos, 1931-1939”. Ayer 27: 163-164.

${ }^{5}$ Las izquierdas no podían hacer suyo un territorio si no lo creaban de nuevo, si no lo consagraban. De ahí que las celebraciones del 1 de mayo de 1931 y 1936 fueran utilizadas para incorporar espacios públicos al nuevo orden proletario, como señala Ramos, M. D. (coord.). 1993. Nuevas perspectivas sobre la Segunda República en Málaga: 71-80 Málaga: Arguval y Velasco Gómez, J. 2008. La Segunda República en Málaga, 1931-1936: 107-124 Málaga. 
necesario, secularizar todos cementerios, desterrar o sancionar impositivamente la exposición de imágenes religiosas en edificios, aunque fueran privados, derribar símbolos y monumentos católicos, etc. $^{6}$

La denominación de las vías públicas, de ciudades y pueblos, de lugares no urbanizados incluso, constituyó una ordenación del espacio que alcanzó el plano de lo inmaterial. Las ideas y valores evocados en los nombres adjudicados configuraban una determinada concepción del mundo, del pasado histórico y del presente vivido que se encontraba en el centro de la relación entre ciudadanos y espacio urbano. El callejero constituyó en las ciudades europeas, que no cesaron de desarrollarse en los siglos XIX y XX, un lugar privilegiado de la historia y de la política, un soporte externo donde éstas se fijaban de contenido y bloqueaba -o al menos así pensaban los administradores del poder- la acción del olvido. Asimismo, el callejero ha constituido un pequeño pero sustancial espacio en que el cualquier régimen, con voluntad de permanencia, ha intentado perpetuarse ante los ciudadanos de su tiempo y futuros. Ello explica las inevitables mutaciones de la denominación de los espacios públicos que han acompañado a todo cambio político. ${ }^{7}$ Desde un punto de vista sociológico, la onomástica espacial era una de las maniobras tradicionales de territorialización que permitió convertir los lugares identificados en identificadores: los nombres de los santos y vírgenes santificaban los sitios, las calles, las plazas, los caminos, las travesías, los terrenos, los edificios, las estaciones de metro...en cuanto los cargaban de la fuerza carismática y salvadora de sus poseedores originales. En Francia y en España, la laicización del espacio - practicada en diferentes geografías y tiempos- implicó una estrategia de desterritorialización, pero ésta fue seguida paralelamente, en todas las provincias, por una reterritorialización secularizadora.

Fuente de inspiración de estas estrategias fue el anticlericalismo francés, de notable influencia en el republicanismo español en tantos aspectos. La revolución de 1789 ya había iniciado una remodelación laicista del espacio público en las ciudades, comenzando por París donde el Faubourg Saint-Antoine se redujo a Faubourg Antoine, Saint-Malo se convirtió en Port Malo y numerosas calles y plazas fueron rebautizadas con el revolucionario santoral laico de la Nueva Francia. En Montmartre se trató de traspasar el capital simbólico martirial cristiano al líder revolucionario asesinado por Carlota Corday, al denominarse Mont-Marat. Toda esa serie de mutaciones fueron suprimidas por distintos regímenes políticos en el siglo XIX pero, en algunos casos y lentamente, volvieron a practicarse en algunas provincias durante la III República, modelo de inspiración de los secularizadores españoles durante más de medio siglo. A partir de 1880, se rebautizaron calles y espacios públicos franceses siguiendo los dogmas laicos, lo cual supuso la eliminación -allí donde se pudo realizar- del callejero de nombres de santos pues, salvo raras excepciones (San Vicente de Paul) fueron considerados neuróticos (San Francisco de Asís, San Benito Labre), histéricos (Santa Teresa de Ávila, Santa Margarita de Alacoque) o crueles (Santo Domingo) por los anticlericales laicistas, los cuales también intentaron

6 Estas transformaciones fueron advertidas por los primeros estudios sobre el anticlericalismo republicano, como en Montero Moreno, A. 1961. Historia de la persecución religiosa en España, 1936-1939: 34-35 Madrid: Biblioteca de Autores Cristianos.

7 Algunos historiadores prefieren utilizar términos como "construcción de la memoria histórica" en vez de "imaginario" e "historia" como Calvo Vicente, C. 1993. "Socialización y espacio urbano: el callejero de San Sebastián durante el franquismo". Cuadernos de Sección. Geografía e Historia 21: 345-356.

${ }^{8}$ Por acuerdo del Consejo Municipal de Madrid, fechado el 4 de junio de 1937, se ordenó enviar un oficio a la Compañía Metropolitana de la capital para que la estación llamada "Iglesia" ostentara el nombre de Sorolla, por estar enclavada en la plaza del mismo nombre, que el 13 de abril de 1932 había sustituido al primero. Aparisi Laporta, L. M. 2001. Toponimia Madrileña. Proceso evolutivo I. Nomenclátor Toponímico: 550, Madrid: Ayuntamiento de Madrid. 
extirpar de su conversación cotidiana el propio sonido "saint". Ante aquellas personas que la Iglesia Católica había elevado a los altares, modelos de excelencia cristiana, los republicanos contrapusieron el de los "verdaderos héroes": los inventores, los descubridores, los hombres de ciencia y progreso. Aquellos a los que Roma había condenado o ejecutado -Galileo Galilei, Giordano Bruno, Étienne Dolet- fueron principalmente honrados, levantándose monumentos y nombrándose vías con sus nombres de manera provocadora. ${ }^{9}$

Al igual que el modelo galo, el cambio de nombre de los espacios públicos que realizaron los munícipes republicanos españoles no sólo tuvo una motivación anticlerical y laicizadora, sino también política, pues se rebautizaron las calles dedicadas a miembros de la Casa Real caída y a políticos y militares ligados a la época monárquica, sobre todo a la Restauración borbónica. Desde sus comienzos, el régimen republicano intentó modificar el imaginario político e histórico de los españoles, socializando a los ciudadanos. Así, entre 1931 y 1933 ese proceso experimentó un acelerado desarrollo tanto a través de la creación de representaciones simbólicas del Estado -la bandera, el himno nacional, las fiestas oficiales, los grupos escolares, las personificaciones femeninas del régimen- como por medio de los nombres de los espacios públicos. ${ }^{10}$

El callejero emitía mensajes en la medida en que perpetuaba o creaba el recuerdo de figuras (Ruiz Zorilla), acontecimientos (revolución asturiana) o fechas (14 de abril) cargadas de significado y contenidos ideológicos, que fueron presentados como paradigmas de la nueva conciencia republicana. Al mismo tiempo, la apropiación nominal del espacio público para configurar un imaginario fue un mecanismo empleado por los republicanos para legitimarse políticamente y construir una continuidad histórica. ${ }^{11}$ Junto a propuestas que afirmaban los valores que animaban a crear conciencia republicana hubo también referencias a aquello que debía ser negado y condenado al olvido y ahí se ubicó el anticlericalismo y el proyecto laicizador. ${ }^{12}$ Para Ángel Luis López Villaverde, a falta de estadísticas precisas, hubo un claro predominio, entre 1931 y 1936, de este segundo objetivo. Su argumentación se apoya en el caso de la ciudad de Cuenca, ya que una de las primeras decisiones de su ayuntamiento consistió en eliminar el nombre de calles, plazas y escuelas con connotaciones políticas del pasado primorriverista o monárquico, quedando intactas las demás, aunque tuvieran claras connotaciones religiosas. Incluso en una ciudad de arraigado pasado anticlerical, Zaragoza, apenas experimentó cambios al respecto. Por contraste, se extendió la sustitución de calles del santoral o con simbología religiosa en Andalucía, con casos tan significativos como los de Écija y Huelva. En todo caso, resulta evidente la necesidad de realizar investigaciones locales para ponderar la verdadera dimensión de esta

${ }^{9}$ Lalouette, J. 1997. “El anticlericalismo en Francia, 1877-1914”. Ayer 27:15-38; Pellistrandi, B. 2007. “Clericalismo y anticlericalismo en Francia ¿Una denominación de origen?” en J. de la Cueva y F. Montero (coords.), La secularización conflictiva. España 1898-1931: 23-38. Madrid: Biblioteca Nueva.

${ }^{10}$ Este proceso es analizado en una ciudad castellana conservadora en Gómez Cabornero, S. 2004. "Identidades políticas en la Segunda República: la construcción de los imaginarios colectivos de los vallisoletanos en los años treinta", en J. Beramendi y M. X. Baz (Coords.). Memorias e identidades, VII Congreso de la Asociación de Historia Contemporánea. Santiago de Compostela: Universidad de Santiago.

${ }^{11}$ El régimen republicano, junto a una reinterpretación del pasado, llevó a cabo una reelaboración de la memoria social, que podemos definir como la apreciación que cada sociedad tiene de su historia y una fijación en la memoria individual de los hechos presentes con el fin de construir y cimentar una visión histórica. Sobre el concepto de "memoria social" seguimos, con matices, a CALVO VICENTE, C. 1993: 346-347.

12 Una renovadora reflexión sobre el estado actual de los estudios sobre el impacto del proyecto secularizador republicano y el abanico de respuestas católicas se encuentra en 2009. Laicismo y catolicismo: el conflicto político-religioso en la Segunda República, J. de la Cueva y Francia Montero (eds.) Alcalá de Henares: Publicaciones de la UAH. 
medida desacralizadora que, en opinión del citado historiador, tuvo un sesgo más laicista que anticlerical. $^{13}$

\section{EL CALENDARIO DE LA SECULARIZACIÓN: LAS VARIACIONES MUNICIPALES}

La constitución y mutación de ayuntamientos durante la Segunda República revelan el calendario de los cambios en los callejeros y los intentos de transformación de los espacios públicos. Pero para comprender cómo operó el poder político en su nivel más básico, el municipal, resulta necesario aludir al papel desempeñado por los gobernadores civiles. Nombrados mediante decreto del Ministerio de Gobernación, desde 1932 esos cargos pasaron a depender de la Presidencia del Gobierno. Esta mudanza conllevó, necesariamente, que las variaciones en la alta política nacional tuvieran su más inmediato reflejo, según las circunstancias, en los cuadros administrativos intermedios y éstos terminaron por hacerlo en la configuración de las células básicas de representación ciudadana, los ayuntamientos. La composición de los municipios podía variar de base -como así ocurrió- de acuerdo a los artículos 52 a 56 de la ley municipal de 1877: esos cambios, por orden del gobernador, fueron conocidos como desmoches, los cuales facilitaron el control del poder local. ${ }^{14}$ De esa manera se explica, durante el régimen republicano, los ceses, las deposiciones y restituciones de alcaldes y concejales, en muchas ocasiones motivados por cuestiones meramente personales y que marcaron el funcionamiento de la vida municipal. ${ }^{15}$

Además de las elecciones del 12 de abril de 1931, se volvieron a convocar -en algunas provincias- nuevos comicios a finales del mes de mayo, como consecuencia de las reclamaciones presentadas en ciertos municipios que impugnaron los resultados de aquéllas. El ministro Miguel Maura apoyó el proceso, ya que, en su opinión, permitiría la definitiva republicanización del poder local, por lo que tampoco se mostró en contra de realizar, si fuera necesario, desmoches. Multitud de ayuntamientos donde habían ganado los monárquicos fueron gobernados por gestoras nombradas por los nuevos detentadores del poder, que expulsaron del poder municipal a los primeros. Una muestra más, según algunos historiadores, de la debilidad que íntimamente tenían algunos líderes republicanos, inseguros todavía de su inesperada victoria política, que no electoral. El 30 de diciembre de 1932, el Gobierno de izquierdas ordenó el cese de todos los concejales elegidos en abril del año anterior por el famoso artículo 29 de la época monárquica. Interinamente, los ayuntamientos fueron sustituidos por nuevas gestoras, dando paso más tarde a elecciones municipales en aquellos lugares afectados por la medida. De ahí que el 25 de abril de 1933 se celebraran nuevos comicios, que dieron el triunfo al

${ }^{13}$ López Villaverde, Á. L. 2008. El gorro frigio y la mitra frente a frente. Construcción y diversidad territorial del conflicto político-religioso en la España republicana: 204, Barcelona.

${ }^{14}$ El gobernador civil, a través de un delegado, se personaba en un ayuntamiento en sesión extraordinaria y, tras las lecturas de rigor, cesaba a unos concejales nombrando a otros. En ciertos casos, con una simple denuncia sobre algunos de ellos o solicitando una inspección municipal sobre ciertas irregularidades de cuentas se podía empezar el proceso de desmoche. En 1934, la revolución asturiana fue la razón política que más impulsó al Gobierno de centroderecha a realizar los cambios municipales. Sánchez García-Saúco, J. A. 2001. "La revolución de Asturias: prólogo de la Guerra Civil española" en A. Bullón de Mendoza Y L. Togores (Coords.). Revisión de la Guerra Civil española: 93-111. Madrid: Actas.

${ }^{15}$ El poder político republicano utilizó los mecanismos necesarios para controlar la ya de por sí estrecha autonomía municipal de muchas regiones como resaltan González Orta, J. I. 2010. "Poder local y democracia municipal durante la Segunda República a través de los ayuntamientos: el caso de Villablanca (Huelva)", Historia Actual online 22: 19-31;Ruiz-Manjón, O. 1979. "Autoridades locales y partidos políticos en Andalucía durante la Segunda República”, Reis. Revista española de investigaciones sociológicas, 5: 150-171. 
centro y a la derecha. ${ }^{16} \mathrm{~A}$ mediados de noviembre, se repitió la victoria en elecciones generales y el vuelco electoral se consolidó, por lo que nuevos gobernadores civiles comenzaron a ejercer desmoches, favoreciendo el cambio político a nivel local, sobre todo tras la revolución asturiana. Ello explica casos como el de la población cordobesa de Doña Mencía, donde, a finales de junio de 1934, todavía los ediles izquierdistas pudieron variar el nombre de las calles de Bendición y Santa María por Pi y Margall y Pérez Galdós, así como la plazuela de la Cruz, transformada en Salmerón. ${ }^{17}$ Tras las elecciones a Cortes del 15 de febrero de 1936, con la victoria del Frente Popular, se volvieron a repetir los desmoches, creándose reiteradamente ayuntamientos de izquierdas.

De esta manera, y según el estado actual de la investigación, los principales cambios en el callejero municipal $-\mathrm{y}$ por ende la desterritorialización y la nueva reterritorialización del espacio público- se produjeron en los periodos de gobierno municipal de la conjunción republicana-socialista (abril de 1931-abril de 1933) y del Frente Popular (febrero 1936-marzo 1939). En la ciudad alicantina de Villena, a los ocho días del cambio de régimen se formó una comisión municipal para estudiar el cambio del callejero e informar posteriormente a los ediles. Las vías de San Francisco, San Antón y de la Verónica recibieron, correspondientemente, los nombres de Niceto Alcalá Zamora, Concepción Arenal y comandante Pastor. ${ }^{18}$ Se potenció, de esa manera, un nuevo santoral laico, donde junto a próceres civiles anticlericales como Marcelino Domingo o Vicente Blasco Ibáñez, figuraron militares como general Riquelme, o mártires republicanos, fueran nacionales -el capitán Ángel García Hernández- y locales, como el guardia municipal Alejo Peña Galán ${ }^{19}$, cuyos nombres sustituyeron, en el callejero del toledano pueblo de Villafranca de los Caballeros, a Isabel la Católica, la Santa Cruz, El Santo, La Virgen y San Juan, respectivamente. En la ciudad catalana de Martorell, a los pocos días de alzarse la bandera tricolor, el ayuntamiento acordó modificar la denominación de calles y barrios con nombres de santos; aunque tardó más tiempo, el de Castuera (Badajoz) por acuerdo municipal de 8 de abril de 1933 decidió que la calle de los Mártires se dedicara a Julián Besteiro, la de la Iglesia a Marcelino Domingo y la de Santa Ana a Margarita Nelken, la famosa diputada socialista anticlerical conocida, desde 1926, por su oposición a conceder el voto femenino ante su temor a que las españolas consultasen antes con sus confesores. ${ }^{20}$ Emilio Castelar desplazó al padre Pascual Ibáñez, misionero en la Islas Filipinas, en el pueblo aragonés de Mallen; de nuevo García Hernández desalojó a la Virgen de la Ascensión en Monforte y en Tarifa se volvió a restaurar la nomenclatura republicana ejecutada en

${ }^{16}$ Estas elecciones fueron consideradas un auténtico plebiscito social contra la política ejercida por la conjunción republicana-socialista en el primer bienio republicano y, especialmente, por su política religiosa y anticlerical. El Gobierno obtuvo 5.048 concejales y la oposición 10.983, de los cuales 4.954 se presentaron en candidaturas de derechas, 2.749 por el Partido Radical, 783 indefinidos, 359 independientes y el resto en diversas candidaturas de extrema izquierda. $A B C, 25$ y 26 de febrero de 1933.

17 Cantero Muñoz, A. 2005. Historia de la Semana Santa de Doña Mencía (1800-2005): 65. Doña Mencía: Ayuntamiento.

${ }^{18}$ Se cambiaron finalmente el nombre de catorce calles. Costa Vidal, F. 1989. Villena durante la II República. Vida política y elecciones: 86-88. Alicante: Diputación. El comandante de aviación Ángel Pastor Velasco, natural de Villena, había participado en la sublevación republicana de Cuatro Vientos en 1930.

${ }^{19} A B C, 9$ de junio de 1931. Alejo Peña fue asesinado por la noche en Villafranca de los Caballeros. Los partidos de izquierda acusaron a la Unión Agraria local del mismo, por haber sido denunciados sus miembros por el guardia municipal, acusándolos de criticar a la República y maniobrar para impedir trabajar a los obreros.

${ }^{20}$ Martín Rubio, Á. D. 1997. La persecución religiosa en Extremadura en la Guerra Civil, Badajoz: Autor Editor. La opinión de Margarita Nelken sobre el voto femenino la expuso ya en los años de la dictadura del general Primo de Rivera, como señala Mangini, S. 1997. Recuerdos de la resistencia, 34-35. Barcelona: Timún. 
1873 proscribiendo la religiosa. ${ }^{21}$ En el jienense pueblo de Porcuna, la plaza de la Cruz se transmutó en Sanchís Banús, neuropsiquiatra socialista, mientras Mateotti desplazaba en una calle al padre Lara, sacerdote y capellán de la ermita de Jesús Nazareno, mientras en la plaza central el ayuntamiento sustituía el monumento al Sagrado Corazón de Jesús -realizado por suscripción popular- por una estatua de Pablo Iglesias.

En las lejanas Islas Canarias, concretamente en Santa Cruz de Tenerife, también se procedió a la variación de nominaciones urbanas tempranamente, trece vías mutaron el 18 de abril de 1931, a propuesta del concejal socialista Pedro García Cabarera, y otras siete el 13 de mayo. Entre ellas, la calle San Francisco de Paula - consagrada a los Estudiantes en honor de aquellos que iniciaron el movimiento opositor contra la dictadura- y la plaza de la Iglesia -dedicada a la fiesta del 1 de mayo-, cuya metamorfosis debía reflejar, en palabras del consistorio, "los sentimientos republicanos y socialistas de estos momentos políticos". Tras las elecciones de febrero de 1936, las plazas de San Telmo y de la Virgen de la Candelaria se transformaron en Adolfo Benítez y República, y la calle de San Carlos en sargento Vázquez, mártir izquierdista de la revolución asturiana. ${ }^{22}$ En el pueblo jienense de Jódar, la calle de la Concepción se transformó en Margarita Nelken a comienzos del mes de junio de ese año, y en Porcuna la plaza de San Juan se transformó en Carlos Marx a los cuatro días de celebrarse las elecciones.

Las innovaciones toponímicas fueron realizadas con notoria publicidad, como en el caso de la ciudad de Málaga donde el 1 de mayo de 1936, como una actividad más dentro del programa de la fiesta socialista, se descubrieron lápidas de las calles Luis de Sirval, Cayetano Bolívar, Aida Lafuente que sustituyeron a las dedicadas, respectivamente, a Santa María, Cruz Verde y Carmen. ${ }^{23}$ En algunos casos, se llegó a laicizar no sólo el callejero sino el mismo nombre de la población, como la gaditana ciudad de La Línea que, por acuerdo municipal de 5 de junio de 1931, borró oficialmente su calificativo "de la Concepción". Esta reterritorialización fue, en la mayoría de los casos, conscientemente provocadora.

Durante el periodo de gobierno del centroderecha (diciembre de 1933-febrero de 1936) se produjeron mutaciones en la rotulación y denominación de vías públicas, pero fueron en menor número y sin que por ello se pretendiera la restauración total de la toponimia monárquica ni de la religiosa, ya que esas medidas hubieran sido consideradas por las izquierdas como una intolerable provocación a la cual hubieran tenido que responder. En todo caso se negaron a continuar esos cambios, pero no se obstaculizaron casos como el sucedido en Santa Cruz de Tenerife, donde se había aprobado, en un acuerdo municipal de 10 de junio de 1931, la nombre de la avenida de Blasco Ibáñez -antes de la Asunción-, pero cuya placa no fue colocada hasta tres años más tarde, aprovechando la visita del hijo del escritor, diputado radical por Valencia. No obstante, algunas poblaciones, al calor de los sucesos revolucionarios de 1934, continuaron desacralizaron calles como en Albacete, donde la calle de la

${ }^{21}$ Figueras, Salmerón, PI, Siñer, etc. desplazaron a la calzada de San Mateo, las calles de San Francisco y Trinidad, la plazuela de San Martín... Segura González, W. 2008. "La I República y el cantón de Tarifa", Aljaranda, 71: 17-27.

${ }^{22}$ Luis, M. J. y Sánchez, J. M. 1995. Historia de Santa Cruz de Tenerife. La Laguna: Comunidad Autónoma. En abril de 1931 también hubo una pequeña resistencia y el concejal socialista no logró variar dos calles con nombres monárquicos.

${ }^{23}$ M. D. Ramos (coord.). 1993: 79-80. 
Virgen se denominó de Asturias, en homenaje a la región sublevada. ${ }^{24}$ Al estallar la Guerra Civil, en la zona controlada por el Frente Popular, las autoridades locales aceleraron el definitivo cambio de nombres de los espacios urbanos y rurales. Se eliminó la presencia de concejales y alcaldes ligados a los partidos de derechas y al Partido Radical Republicano, siendo sustituidos por representantes del cartel electoral de izquierdas o por anarquistas. En Cataluña, todos los pueblos, ciudades y lugares que mantenían la advocación de un santo fueron suprimidos oficialmente por decisión municipal, refrendada por el Gobierno de la Generalitat: se realizaron en total 92 cambios. En San Feliú de Guixols desapareció la primera palabra, mientras otros municipios buscaban un nuevo nombre en el paisaje o en el imaginario anarquista o comunista que les rodeaba, y que no recordara, lógicamente, al santoral. San Font de Lluçanes se convirtió en Aurora de Lluçanes, San Climent del Llobregat en Cirerer de Llobregat. ${ }^{25}$ Los nombres de las calles con connotaciones religiosas también sufrieron mutaciones obligadas. El ayuntamiento de Manresa acordó la sustitución de 32 espacios públicos en septiembre de 1936, de tal manera que la calle de San Miguel se transformó en Ferrer i Guardia, la de los Capuchinos por Hermanos Ascaso -militantes de la FAI-, San Lorenzo por Karl Marx. ${ }^{26}$ El ejemplo catalán se extendió a otros lugares; en Cartagena, por ejemplo, la diputación de Santa Ana fue transformada en Leopoldo Alas -escritor también distinguido por su crítica anticlerical- el 14 de julio de 1937.

Entre 1931 y 1939, para las bases sociales republicanas, la política municipal de reordenamiento de espacios públicos formó parte de un punto esencial de su cultura política, el anticlericalismo, el cual continuaba siendo una herramienta discursiva de fácil acceso. Y para hacer frente al clero no cabía sino la confrontación directa con el mismo y con sus seguidores católicos, lo cual implicaba la imposición de reformas, límites legales, prohibición de actividades o bien su persecución hasta su definitiva erradicación. ${ }^{27}$ Este discurso estaba ya asumido por otros partidos de izquierda a la llegada de la Segunda República, por lo que no resultó extraño que sus líderes y bases lo apoyaran igualmente. Para muchos católicos, resultó más comprensible la sustitución de nombres y símbolos ligados a la Monarquía -al formar parte de los rituales de victoria de los republicanos- que el relevo de calles y lugares públicos ligados al santoral y a la simbología cristiana, considerado una humillación, un ataque gratuito, una ofensa, una herida más ya que, en algunos casos, se impusieron a esas vías nombres de personajes combativamente anticlericales o antirreligiosos. ${ }^{28}$ Con el paso del tiempo, en muchos

24 Delgado Ruiz, M. 2001. Luces iconoclastas. Anticlericalismo, espacio y ritual en la España contemporánea: 49. Barcelona: Ariel. Los cambios en el callejero son definidos por el autor como una "concienzuda acción" por borrar lo sagrado de la vida cotidiana.

${ }^{25}$ Un desglose detallado de las mutaciones en el nomenclátor de las poblaciones de La Selva, en Gerona, aparece en Comas, D., Goñi, J., Pujol, D. 1991. "La revolució i el poder local a la comarca de La Selva a l'estiu de 1936. El cas de Brunyola", Quadern del Cercle d'Estudis Historics $i$ Socials, 7: 223-236.

${ }^{26}$ La obsesión por la redefinición nominal llegó al extremo de conceder un cambio oficial de apellidos a fin de evitar que un ciudadano tuviera que soportar la vergüenza de llamarse "de Dios". Alberti J. 2008. La Iglesia en llamas. La persecución religiosa en España durante la Guerra Civil: 439-440. Barcelona: Destino.

${ }^{27}$ Cueva, J. 2007. "Cultura republicana, religión y anticlericalismo: un marco interpretativo para las políticas laicistas de los años treinta” en J. Dronda Martínez y E. Majuelo Gil (eds.). Cuestión religiosa y democracia republicana en España (1931-1939): 55-57. Pamplona: UPN. Sobre los cauces de extensión del anticlericalismo y sus diversas ramas bajo la Restauración ver Martín Rubio, Á. D. 2002. "Educación y formación de una mentalidad anticlerical en España (1875-1931)", Aportes. Revista de Historia Contemporánea, 49: 74-89.

${ }^{28}$ El diferente abanico de respuestas católicas a la política anticlerical y secularizadora es analizado por Hernádez Figueiredo, J. R. 2009. Destrucción de del patrimonio religioso en la II República (1931-1936) a la luz de los informes inéditos del Archivo Secreto Vaticano, Madrid: Biblioteca de Autores Cristianos. La destrucción de edificios religiosos que se analiza en este libro también formó parte de la desterritorialización del espacio público, ya que, tras su desaparición física, podrían construirse en sus solares nuevos edificios que 
núcleos urbanos se observó una resistencia pasiva a esta mutaciones, como en Santa Cruz de Tenerife donde el concejal González Trujillo protestó públicamente por esa desobediencia civil, como se podía comprobar en algunos periódicos, donde los anunciantes continuaban rotulándose con los nombres del antiguo callejero, negándose a reconocer los otorgados por la conjunción republicana-socialista. ${ }^{29}$ En Porcuna (Jaén) un grupo de vecinos logró que la calle dedicada al beato Garrido, mártir en Argel, recuperara su nombre el 3 de junio de 1933, desplazando al escritor socialista y anticlerical Tomás Meabe con el que se había rebautizado a las pocas semanas de implantarse el régimen republicano. Se volvió a demostrar, así, una realidad de la política municipal: el urbanista nunca tiene del todo garantizadas la lealtad y la sumisión del urbanizado. ${ }^{30}$

\section{ANÁLISIS DEL CALLEJERO MADRILEÑO}

Como puedo comprobarse en el apéndice final, en Madrid el establecimiento de nuevos contenidos fue perpetrado en varios momentos, fundamentalmente en los meses inmediatos a la proclamación de la república en 1931, en las semanas posteriores a la victoria del Frente Popular en febrero de 1936 y en aquellas que siguieron a la formación del Gobierno Largo Caballero, durante la guerra civil. ${ }^{31}$

\section{A. $\quad$ Etapa abril 1931-octubre 1933.}

A los pocos días del cambio de régimen, el nuevo consistorio municipal comenzó el cambio del nombre de las calles, plazas, glorietas y diversas vías urbanas, bajo la presidencia de Pedro Rico López, que sustituyó al liberal Joaquín Ruiz Jiménez. ${ }^{32}$ La capital de España debía dejar de ser la Villa

secularizarían arquitectónicamente los núcleos urbanos. El mismo día en que el ayuntamiento de Madrid decidía un elevado número de cambios en el callejero también se aprobó la destrucción de la iglesia de las Calatravas en la céntrica calle Mayor, como destacó $A B C$ el 8 de agosto de 1931. Desde un punto de vista antropológico y sociológico, la destrucción anticlerical es diseccionada por DELGADO RUIZ, M. 2001.

${ }^{29}$ Galán Gamero, J. 1995. Historia de la prensa en Santa Cruz de Tenerife: 56. Tegueste. Algunos historiadores concluyen que el proyecto de construcción de un imaginario republicano que dotara de identidad y estabilidad al Estado a través de la comunicación de la cultura política propia de la república asumida por una mayoría de la población fracasó en numerosos lugares. Para el caso de Valladolid, Gómez Cabornero, S. 2002.

${ }^{30}$ Delgado, M. 2007. Sociedades movedizas. Pasos hacia una antropología de las calles: 16. Barcelona: Anthropos.

${ }^{31}$ Sobre la toponimia madrileña existe una variada red de estudios locales: Repide, P. de. 1998. Las calles de Madrid. Madrid: Avapiés; Argüelles Garrido, J. M. y otros, 1989. "Aportación documental al estudio del callejero madrileño (1860-1967”, Anales del Instituto de Estudios Madrileños (en adelante, AIEM) III: 451478; Oliva Escribano, J. L. 1994. "Calles y plazas madrileñas (bibliografía)”, AIEM XI: 373-390; Rubio Pardos, C. 1988. "El uso de patronímicos en los nombres de las calles de Madrid", AIEM II: 451-480; Sainz de Robles, F. C. 1988. "El disparadero disparatero del callejero madrileño", AIEM II: 427-445.

${ }^{32}$ Pedro Rico López fue alcalde del 15 de abril de 1931 al 6 de octubre de 1934, perteneciente al Partido Republicano Federal. Debido al estallido de la revolución asturiana fue destituido. En 1936 nuevamente fue repuesto en el consistorio por un trasmoche, esta vez por Izquierda Republicana, desde el 20 de febrero hasta el 7 de noviembre en que, tras intentar huir de Madrid fue detenido por los anarquistas en Tarancón, por lo que al regresar a la capital solicitó asilo diplomático en la embajada de México. Evacuado a Francia y Bélgica, regresó a las Cortes de Montserrat para intentar cobrar su sueldo de diputado. Contacto con autoridades franquistas para volver a España, reconociendo al nuevo régimen en 1938, pero no se le permitió su retorno. Archivo del Ministerio de Asuntos Exteriores, R. 1060, exp. 135. 
y Corte de la Monarquía secular para transformarse en un nuevo París, en una urbe nueva, espejo donde reflejar la imagen del nuevo régimen y republicanizar, por extensión, a las demás ciudades españolas. La actitud de los concejales monárquicos fue de absoluta abstención, consecuencia de esa mezcla de sorpresa, estupor, pesimismo, resignación y miedo que les paralizó, situación que prácticamente, se reprodujo en todas los municipios surgidos del 12 de abril con mayoría republicanasocialista. De esa manera, las actas municipales no reflejan incidentes, ni conflictos políticos ni protestas acaloradas por los cambios en el callejero. Como en tantos otros núcleos de población, el ayuntamiento madrileño comenzó la labor de sustitución del callejero monárquico por otro republicano, labor que, fundamentalmente, se realizó en los siguientes seis meses. Las calle de Alfonso XII pasó a ser Niceto Alcalá-Zamora; la avenida Reina Victoria, la de García Hernández; la avenida de Alfonso XII se tildó del Empecinado en el mes de agosto, pero en septiembre el consistorio municipal la varió por Carlos Marx; la calle de la Princesa se transformó en Vicente Blasco Ibáñez. Situación que se repitió en pueblos cercanos a la capital, y en aquellos absorbidos por la gran urbe, pues la calle Reina Mercedes, en Fuencarral, se tituló Cervantes; la de Alfonso XIII, en Villaverde, se bautizó por República o Galán y Hernández en otros lugares próximos. ${ }^{33}$ En general, y como en el resto de España, se sustituyeron las calles por el nuevo santoral republicano: mártires como los capitanes Galán y Hernández, políticos, intelectuales, símbolos y líderes ideológicos republicano-socialistas.

Desde la prensa monárquica comenzó a manifestarse su malestar por esos cambios. En la influyente tercera de $A B C$, Ramón López Montenegro firmó "Nomenclación" donde calificaba las mutaciones en el callejero como infantiles pero perturbadoras, en muchos casos injustas -Federico Chueca no tenía todavía una vía pública a su nombre- y sólo significaban una satisfacción pueril pues "al pueblo no le sacan de su plaza Mayor, como no le sacan de su Cibeles ni de su Cedaceros" pese a la gran cantidad de cambios municipales realizados en el siglo XIX. En su opinión, el nombre de las vías públicas viejas debía ser respetado, y las nuevas debían titularse con nombres cribados por la historia. $^{34}$

Pero sus críticas fueron inútiles: la misma clase de nueva toponimia se aplicó en la laicización del callejero que aludía al catolicismo. Se bautizaron calles con el nombre de líderes históricos de la conjunción victoriosa como los republicanos Nicolás Salmerón y Emilio Castelar, o socialistas como Jaime Vera y Pablo Iglesias -fundadores del PSOE-, Luis Fernández Martínez- sindicalista-, así como de los nuevos protagonistas como Eduardo Ortega y Gasset - primer gobernador civil de Madrid con la república, fiscal general, abogado del Socorro Rojo Internacional- o Julián Besteiro, lo cual fue considerado un gesto de prepotencia por muchos observadores conservadores. ${ }^{35}$ Tras la quema de conventos y edificios religiosos desarrollada entre los días 10 y 13 de mayo, el consistorio municipal retomó la reforma del callejero religioso sustituyéndolo por iconos culturales de las izquierdas como los escritores Enrique de la Mesa y Rosalía de Castro, periodistas como Roberto Castrovido -miembro del Partido Republicano Demócrata Federal, integrado en la Alianza Republicana-, Rosario Acuña feminista y librepensadora-; José Nakens; socialistas como Francisco Largo Caballero. ${ }^{36}$ Paralelamente, el Gobierno Provisional aprobó un aluvión de disposiciones que secularizaron la vida pública: libre enseñanza de la instrucción religiosa en los centros estatales ( 6 de mayo), supresión de

${ }^{33}$ Archivo de la Villa de Madrid (en adelante, AV), Acuerdos Municipales (1931), 15 y 28 de abril, 20, 29 y 30 de mayo, 25 de septiembre y 9 de diciembre.

${ }^{34} A B C, 28$ de abril de 1931, p. 3. Ramón López Montenegro fue periodista, compositor, autor teatral y caricaturista del diario monárquico.

${ }^{35}$ Debe tenerse en cuenta que el cambio de nombres por los aludidos se realizó en los primeros quince días de régimen republicano. AV, Acuerdos Municipales (1931), 19, 21, 26 y 28 de abril.

${ }^{36} \mathrm{AV}$, Acuerdos Municipales (1931), 17, 25 y 29 de mayo, 3,5 y 24 de junio, 3, 7 y 12 de julio. 
exenciones tributarias a la Iglesia católica ( 8 de mayo), plena libertad de conciencia y culto (22 de mayo), anulación de la obligatoriedad de asistencia a actos religiosos por parte de miembros del ejército (18 de abril), secularización de cementerios (9 de junio). La práctica de ese trágala -todavía sin haberse elegido Cortes Constituyentes- creó una irritante humillación cotidiana, durante esos meses, para los católicos.

Fue en la sesión municipal del 7 de agosto de 1931 cuando se aprobó un aluvión de cambios en el callejero religioso: hasta 30 vías urbanas llegaron a ser rebautizadas con mitos históricos del republicanismo (los comuneros Padilla, Bravo y Maldonado, la Ilustración), con los miembros del panteón nacional español (Goya, El Greco, Albéniz, Murillo, Don Quijote, Tomás Bretón, Concepción Arenal, Agustina de Aragón, Pérez Galdós, Leonardo Torres Quevedo ${ }^{37}$ ), con el nuevo vocabulario simbólico del régimen (Cuatro Vientos ${ }^{38}$, Amnistía, Conjunción, Igualdad, Progreso, Artes, Proletario, Mártires de Chicago), con políticos socialistas como Manuel Llaneza -diputado, secretario del sindicato minero asturiano, delegado español en la Internacional de Obreros Mineros- republicanos como Gumersindo de Azcárate y Marceliano Izábal, con líderes y personajes republicanos bajo la Restauración (Ruiz Zorrilla, el general golpista Villacampa, el médico Federico Rubio). ${ }^{39}$ Ese mismo día, se publicaba el nuevo plan de estudios del bachillerato de Marcelino Domingo, por el cual la enseñanza de la religión se reducía a un curso, sin carácter confesional y voluntaria. Al año siguiente tan sólo se cambió el nombre de seis vías con nombres religiosos, reduciéndose a cuatro y tres en el bienio posterior, aplicando los mismos objetivos: creación de representaciones simbólicas del nuevo régimen (República), personas convertidas en modelos ideológicos para la ciudadanía republicana (Rosario Acuña, Francisco Ferrer), líderes políticos (Manuel Llaneza, diputado socialista; Joaquín Ruiz Jiménez, liberal $^{40}$; el concejal Armengot ${ }^{41}$ ) o personajes de la cultura española (escritor Roque Barcia, la actriz María Guerrero, Concepción Arenal ${ }^{42}$, pintor Sorolla) o de notoria popularidad (la pareja de actores Loreto Prado y Enrique Chicote).

La toponimia religiosa, anterior a estas reformas, aludía a nombres de santas y santos, mayoritariamente, aunque también fueron numerosas las vías que habían sido consagradas a la Virgen María, a la Iglesia o a edificios religiosos, tanto templos como hospitales (calle de Misericordia ${ }^{43}$ ), la

${ }^{37}$ Leonardo Torres Quevedo (1852-1936), ingeniero de caminos, inventor de un dirigible, presidente de la Academia de Ciencias Exactas y de la Lengua Española.

38 Alusión al aeropuerto militar madrileño de Cuatro Vientos, fundado en 1911. El general Queipo de Llano y el comandante Ramón Franco, junto a algunos civiles, se apoderaron del aeródromo el 15 de noviembre de 1930. Se unieron a los conspiradores una parte de las fuerzas acuarteladas y bombarderon la capital con propaganda republicana, divulgando por la radio la proclamación de la república. Finalmente fueron derrotados por las fuerzas fieles a la monarquía.

${ }^{39}$ AV, Acuerdos Municipales (1931), 7 de agosto. En la misma línea, el día 19 la calle de la Iglesia, en el distrito de Hortaleza, pasó a titularse Cervantes.

${ }^{40}$ Joaquín Ruiz Jiménez (1854-1934), periodista andaluz, diputado y senador, fue concejal de la Villa y Corte desde 1893 y alcalde en cuatro ocasiones por el partido liberal. En 1916 fue ministro de la Gobernación, llegando a ser vicepresidente del Congreso y gobernador civil de Madrid.

41 Joaquín Armengot y Armengot (-1944), maestro de obras, fue concejal y alcalde de Carabanchel Bajo entre 1934 y 1936.

${ }^{42}$ El ayuntamiento madrileño ya había dedicado dos calles a Concepción Arenal bajo la Monarquía: en el distrito centro en 1921 y en Carabanchel en 1923.

${ }^{43}$ El hospital de la Misericordia fue fundado por doña Juana de Austria en 1559, con el objeto de atender a sacerdotes pobres. 
popular inclusa ${ }^{44}$, capillas (calle de Nuestra Señora de los Dolores, del Divino Redentor ${ }^{45}$ ), conventos (calle de la Victoria, del Carmen ${ }^{46}$ ), el seminario y devociones populares (calle del Amor de Dios ${ }^{47}$, sagrado corazón, rosario). Igualmente, no habían faltado referencias al papel desarrollado por las órdenes religiosas (jesuitas, carmelitas descalzos, capuchinos, beata María Ana de Jesús, mercedaria) y eclesiásticos (cardenal Mendoza, nuncio).

¿Hasta qué punto estas medidas de reterritorialización pueden ser calificadas como simplemente laicas o intencionadamente anticlericales? Tras los incendios de mayo de 1931, fue bautizada la calle del Amor de Dios por Roberto Castrovido el cual había escrito en El País que esa quema de edificios religiosos acreditaba el "indudable progreso en la moral, sensibilidad $y$ humanitarismo del pueblo, o, si se quiere, del populacho", ${ }^{48}$ la céntrica calle del Carmen fue titulada de José Nakens, famoso republicano anticlerical, que había soñado siempre con una república traída por la fuerza, sangrienta, dura y justiciera. En 1881 había fundado el conocido periódico El Motín "para quitar la influencia del cura y del fraile", que se transformaría en un semanario satírico y rabiosamente anticlerical; en 1903 impulsó el partido republicano liderado por Salmerón, al que retiró su apoyo por su escasa vocación violenta y revolucionaria, y no dudó en ocultar al terrorista Mateo Morral, tras cometer el atentado contra los reyes el día de su boda, que se saldó con decenas de muertos y heridos. En 1909 excusó y elogió los incendios de edificios religiosos durante la Semana Trágica de Barcelona. ${ }^{49}$

La calle del Buen Suceso ${ }^{50}$ quedó desacralizada el 20 de noviembre de 1931 al dedicarla a Mario Roso de Luna, político republicano, impulsor de la teosofía, conocido como el mago de Logrosán. ${ }^{51}$ Ningún observador contemporáneo ocultó la victoria simbólica que representó la sustitución de la calle de Los jesuitas y del paseo de Los jesuitas - bestias negras del anticlericalismo republicano- por el nombre de la escritora masona Rosario Acuña, sumamente crítica con el catolicismo y famosa por

${ }^{44}$ La inclusa o casa real de Nuestra Señora de la Caridad y San José, dedicada a recoger niños abandonados, levantada por la cofradía de la Soledad, integrada en el convento de mínimos de la Victoria.

${ }^{45}$ La capilla de Nuestra Señora de los Dolores se encontraba en el cementerio de San Ginés y San Luis. La del Divino Redentor se había levantado en 1927, dependiente de la iglesia de las Victorias.

${ }^{46}$ El convento de la Victoria fue fundado en 1561 por fray Juan de la Victoria, abulense fallecido en Madrid. Fue administrado por las religiosas de San Francisco de Paula, el cual fue derruido en 1836 por la desamortización liberal de Mendizábal, pasando a ser propiedad de Manuel Matheu, íntimo del ministro. El convento de San Dámaso fue conocido por del Carmen al encontrase regentado por religiosos descalzos carmelitas, establecido en el siglo XV. En la fachada aparecía una imagen de la Virgen del Carmen, que se encuentra actualmente en la capilla del hospital público Gregorio Marañón. Del convento tan sólo permanece la iglesia del Carmen y San Luis.)

${ }^{47}$ La Virgen del Amor de Dios fue una popular imagen que se adoraba en el portal de una casa cercana a la huerta de los jerónimos. Ante el fervor de los madrileños, el nuncio dispuso el traslado de la imagen a la iglesia del colegio de niños desamparados.

48 Roberto Castrovido (1864-1940), escritor y periodista madrileño, llegó a ser director de El País y diputado. En 1930 el Ayuntamiento de la capital intentó concederle su medalla de oro pero se negó a aceptarla de un consistorio monárquico, por lo que no dudó en recibirla cuando se la ofreció uno afín al Frente Popular el 21 de febrero de 1936.

${ }^{49}$ El Motín, 14 de octubre de 1909, p. 2.

${ }^{50}$ Mención a la iglesia y hospital del Buen Suceso (siglo XV). En el hospital se encontraba una imagen de la Virgen que fue hallada por dos frailes, camino hacia Roma, al refugiarse en una cueva. Al ser bendecida por Paulo V, exclamó que había sido un buen suceso.

51 Mario Roso de Luna (1872-1931) ejerció el periodismo, la política, la astronomía, fundó varias sociedades teosóficas en Extremadura; fue considerado por los republicanos como un hombre de ciencia enfrentado al oscurantismo clerical y católico.

Hispania Sacra, LXIV, Extra I, enero-junio 2012, 47-68, e-ISSN: 1988-4265, doi: 10.3989/hs.2012.026 
haber firmado en 1907 su testamento donde certificó públicamente su separación de la religión, su vida y muerte alejada radicalmente de la Iglesia, previniendo que, en caso de último arrepentimiento, se le considerara demente. ${ }^{52}$ La popular calle del Sacramento recibió el nombre de Pablo Lafargue, anticlerical decidido, para el cual el socialismo estaba obligado a "combatir a los curas porque son explotadores capitalistas y servidores de los mismos". Dedicar a Pablo Iglesias una vía ¿era una victoria sobre el clero y los católicos? Se trataba del líder socialista que había declarado, en 1903, que el clericalismo no podía ser herido de muerte en plena sociedad capitalista, por lo que -al igual que el militarismo- no podría desaparecer hasta que el proletariado se instalara por completo en el poder ${ }^{53}$. La misma pregunta surge ante la desterritorialización de la calle de la Inmaculada, bautizada con el nombre de Eduardo Ortega y Gasset, uno de los miembros más destacados del partido radicalsocialista, agrupación política que hacía gala de un anticlericalismo irresponsable. ${ }^{54}$

Una calle dedicada a San José se mutó en Pérez Galdós, pero ¿hasta qué punto era una figura del panteón nacional o un escritor anticlerical famoso por la repercusión social de su influyente y escandalosa Electra en 1901? Era el mismo Benito Pérez Galdós, activista republicano, que en un mitin anticlerical de 1908 en Santander afirmó ante su auditoría que se debía "eliminar para siempre la acción teocrática de la esfera política, extinguir el miedo religioso, y alejar del suelo patrio los poderes exóticos y nada espirituales que vienen a dirigir nuestra política, a embobar nuestras almas, para encarnarse en nuestros cuerpos y hacerse dueños de toda la vida española, y a trincar con dura garra la enseñanza pública, para moldear a su imagen las generaciones venideras". ${ }^{5}$

En marzo de 1933, bajo la presidencia del alcalde Pedro Rico, partidario y patrocinador de los cambios en el callejero -conocido vocal del Gran Consejo Federal Simbólico del Grande Oriente Español- se intentó sustituir la avenida de San Isidro por la de Francisco Ferrer y Guardia: se llegó al extremo de provocar a los católicos al eliminar el santo patrón de Madrid por el pedagogo anarquista y fundador de la Escuela Moderna, implicado en los sucesos anticlericales de la Semana Trágica de Barcelona. Tras un debate, la propuesta no prosperó por el alcance ya ilimitado que supondría para los madrileños, tanto católicos como indiferentes. ${ }^{56}$ Tampoco debe olvidarse que se adivinaban cambios políticos, pues ese mismo mes las elecciones municipales celebradas supusieron una derrota de la conjunción social-azañista. Tras los sucesos de la revolución de octubre de 1934, el alcalde Pedro Rico fue sustituido por políticos de centroderecha como José Martínez de Velasco (Partido Agrario), Rafael Salazar Alonso (Partido Radical) y Sergio Álvarez de Villaamil (Independiente). Durante su gestión municipal no se produjeron cambios políticos o secularizadores del callejero municipal, los cuales se retomaron tras la victoria electoral del Frente Popular, en febrero de 1936, que ordenó a sus nuevos gobernadores civiles el cambio de alcaldes y concejales. Pedro Rico volvió a ostentar la vara municipal y se inició, nuevamente, una reterritorialización del espacio público.

52 González Seoane, M. 2006. "Rosario de Acuña: a masona (1851-1923)". Andaina. Revista do Movemento Feminista Galego, 45: 52-53; Fernández Morales, M. 2006. Rosario de Acuña, Oviedo: Milenta Muyeres y Ayuntamiento de Gijón.

${ }_{53}$ Arbeloa, V. M. 1973. Socialismo y anticlericalismo: 158-159 y 179-180. Madrid: Siglo XXI. Ambos líderes socialistas concluían que el anticlericalismo burgués no debía confundirse con la lucha del movimiento obrero contra el clero.

${ }^{54}$ El programa anticlerical del partido es analizado por Álvarez Tardío, M. 2011. "La democracia de los radical-socialistas", F. del Rey(dir.), Palabras como puños. La intransigencia política en la Segunda República Española: 281. Madrid: Tecnos.

55 Miranda, S. 1982. Religión y clero en la gran novela española del siglo XIX: 149-150. Madrid: Rialp.

${ }^{56}$ AV, Acuerdos Municipales, (1933), 10 de marzo. 
B. $\quad$ Etapa febrero-septiembre de 1936.

El carácter político fue la nota predominante en este periodo, ya que sólo la plaza del Rosario se retituló con el nombre de Cervantes, una figura del imaginario nacional. Varias calles de carácter religioso fueron bautizadas con los nombres relacionados con la revolución de 1934, reivindicada por la unión electoral de izquierdas, la cual había prometido la amnistía para aquellos que todavía se encontraban encarcelados por su participación en ella. Era una simbólica victoria sobre los clericales de la CEDA, a quienes la propaganda de izquierdas no había cesado de convertir en los grandes culpables de la represión posterior al intento revolucionario, que tuvo sustanciales violencias anticlericales. ${ }^{57} \mathrm{De}$ ahí las calles dedicadas al periodista valenciano Luis Sirval -seudónimo de Luis Higón Rosell, fallecido durante la lucha ${ }^{58}$-, a Ramón González Peña - principal líder socialista de la revolución-, al sargento Diego Vázquez -que desertó del ejército para unirse a los sublevados por lo que fue fusilado-; al Mártir Emilio Gudiel -otro líder revolucionario que sustituyó al Amor hermoso ${ }^{59}$, culminando este proceso con la calle dedicada, en general, a los Mártires de Octubre.

También se dedicaron vías a personajes relacionados con el victorioso Frente Popular como Juan José Mansó del Abad, diputado comunista, involucrado en el asesinato del exministro de Trabajo Alfredo Martínez; al político socialista Carlos Rubiera Rodríguez (dos calles), que llegaría ser gobernador civil de Madrid durante los meses de mayor represión política (octubre-diciembre de 1936) y mano derecha del ministro Ángel Galarza durante la guerra. Fue sintomático el nombre de Dieciséis de febrero que se otorgó al paseo alto de la Virgen del Puerto, fecha de la reciente victoria electoral, en un claro ejercicio de prepotencia política y desafío a los católicos.

\section{C. $\quad$ Septiembre 1936-mayo de 1937.}

El 4 de septiembre fue nombrado el nuevo Gobierno de Francisco Largo Caballero, que sustituyó al anterior gabinete de izquierda burguesa. Al violento calor de la guerra civil, como en otras poblaciones bajo control de la España del Frente Popular, se procedió a una nueva rotulación de calles, desapareciendo referencias religiosas, que en Madrid fueron sustituidas por el nombre de milicianos muertos en acción bélica, sobre todo en los combates del frente de Somosierra. De ahí las vías dedicadas a Mendoza y Hernández, al teniente Carlos Pérez, Dionisio Pérez y José Duro ${ }^{60}$.En la sesión del consejo municipal de 14 de mayo de 1937 se propuso la asignación completa de nombres a milicianos caídos a topónimos relacionados con santos y santas, pero la cuestión quedó pendiente de aprobación final.

${ }^{57}$ La mayoría de los 34 eclesiásticos asesinados en las jornadas de octubre de 1934 fueron víctimas de la represión indiscriminada de los revolucionarios, como subraya Cueva J. de la. 1998. "El anticlericalismo en la Segunda República y la Guerra Civil”, E. La Parra y M. Suárez (eds.), El anticlericalismo español contemporáneo: 251 Madrid: Biblioteca Nueva.

${ }^{58}$ Luis Higón Rosell (1894-1934) fue redactor de La Voz de Valencia, El Diluvio de Barcelona y La Libertad de Madrid.

${ }^{59}$ En la iglesia de San Ginés existe todavía una imagen bajo la advocación de Nuestra Señora de todos los santos y madre del Amor hermoso, que fue destruida por los milicianos en 1936. Mariano Benlliure realizó una copia en la posguerra. El nombre fue propuesto por la comunidad de monjas de Almendrales.

${ }^{60}$ AV, Actas Municipales (1936), 13 de septiembre. 
También se acordó reterritorializar con nombres relacionados con la historia del socialismo y del anticlericalismo como Tomás Meabe (1879-1915), que sustituyó al cardenal Mendoza en una calle. Este escritor vasco sufrió una crisis religiosa que le hizo ateo militante, no dudando en manifestar por escrito que su fe caminaba "al sol del socialismo, nuevo sol de mi vida". Su anticlericalismo extremo fue considerado inoportuno por Facundo Perezaga, líder socialista vasco a comienzos del siglo XX. Otros homenajeados fueron Pablo de Laforque (1842-1911), médico y político, nacido en Santiago de Cuba, casado con Laura Marx; Federico Engels; el diputado italiano Santiago Matteotti, asesinado por los fascistas y considerado un mártir socialista; o los periodistas y tipógrafos José Mesa Llompart, que intervino en la AIT de 1866, y Fernando de Roca. En esa misma sesión municipal se rebautizaron varias calles con nombres de intelectuales reivindicados por la izquierda española como Máximo Gorki y Carlos (Charles) Darwin, cuyas teorías sobre la evolución había generado un decisivo debate entre religión y ciencia. Tan sólo la calle de San Bruno fue titulada con un nombre apolítico: Alcantarilla de la Cava Baja. ${ }^{61}$

Manteniendo la resolución desarrollada en los meses anteriores, se volvió a exaltar a los participantes en la revolución asturiana, dedicándose una calle a Javier Bueno, antiguo militante del Partido Radical-Socialista, periodista socialista encarcelado por su participación en esos hechos, presidente de la junta que se incautó de la Asociación de Prensa madrileña y de varios periódicos conservadores. Quizá ante el cierre de la nunciatura, se cambió la calle del Nuncio por la de Ricardo Villa (1871-1935), fundador y primer director de la banda municipal, resultando manifiesta la intención populista de los concejales por convertir a personas relacionadas con el mundo de la cultura y el arte -no vinculadas a las élites tradicionales- en protagonistas de la historia, en plena coyuntura bélica. De ahí que en esa misma sesión municipal se acordara dedicar vías urbanas a la escritora Carmen de Burgos (Colombine), a León Tolstoi y al poeta Francisco Villaespesa. ${ }^{62}$

El 7 de mayo de 1937 se acordó la supresión total y completa del callejero madrileño de cualquier referencia al santoral. La presión de los comunistas y de los anarquistas para reterritorializar el espacio urbano, durante este último periodo de existencia del régimen republicano, se unió a los de socialistas y republicanos en toda la España del Frente Popular. El semanario anarquista de Alcoy, Ruta confederal, -al igual que en otros lugares- reclamó un cambio profundo en el nomenclátor callejero ese mismo año:

"Hay todavía multitud de calles de Alcoy rotuladas con nombres de santos y santas. Esto para un pueblo de la tradición democrática y revolucionaria del nuestro es una contradicción, por no calificarlo de manera peor, que es como se merece. Mosén Torregrosa, Purísima, Santa Lucia, San Buenaventura, Cura Navarro, Cura Belloc, etc. Esto da la sensación de un pueblo dominado por la reacción católico-fascista. Alcoy debe de rotular las calles que aún conserven los nombres religiosos o reaccionarios, con nombres modernos, actuales, alusivos a la memoria de los mártires de nuestra independencia patria, evocadores de hombres libres y cultos. Miles de héroes caídos en esta guerra dura merecen que los pueblos les ofrezcan este homenaje. No más nombres de calles que recuerden a la piara religiosa. No más nombres civiles que

${ }^{61} \mathrm{AV}$, acta municipal de 2 de octubre de 1936.

${ }^{62}$ Ibídem. Todos los acuerdos de cambio se realizaron bajo presidencia de Pedro Rico. El 8 de noviembre de 1936 fue sustituido por Cayetano Redondo Aceña, el cual pasó el testigo del consejo municipal a Rafael Henche de la Plata, ambos del PSOE, el 23 de abril de 1937, que permaneció en su puesto hasta el final de la desaparición del régimen republicano. Carmen de Burgos Seguí (1876-1932) destacó en el periodismo y la novela, ejerciendo como profesora de Lengua y Literatura en la Escuela Femenina de Magisterio de Madrid. 
recuerden a personajes de triste memoria. No más nombres teológicos que redivivan la farsa y la mentira religiosa. ${ }^{63 "}$

De esa manera varias calles madrileñas con referencias religiosas fueran rotuladas -sin necesidad de acuerdo municipal previo- con nombres como Liberación; Mateo Morral; Joaquín Dicenta, no quedando claro si Benedicto, escritor ateo, anticlerical, republicano, o su hijo Alonso, popular dramaturgo de la época; y María Silva Cruz la libertaria, la única anarquista homenajeada, nieta del famoso Seisdedos, una de las dos personas que sobrevivieron a la quema de la casa y, por lo tanto, ligada a los luctuosos hechos de Casas Viejas, que moriría fusilada al inicio del conflicto cainita. La calle de Recoletos -agustinos recoletos- fue conocida como Luis Rufilanchas, fundador de la FUE, abogado y miembro activo de las juventudes socialistas. Hasta ese momento, 103 vías públicas habían sido secularizadas bajo el régimen republicano mediante acuerdo municipal en la capital.

\section{CONCLUSIÓN}

Si bien el conflicto entre anticlericalismo, secularización, catolicismo y clericalismo tuvo categoría de problema nacional de trascendencia general durante la década de los años treinta del siglo $\mathrm{XX}$, no debe olvidarse que se dilucidó a través de dinámicas locales desiguales y se robusteció por estímulos municipales. La reelaboración del callejero constituyó un lugar privilegiado para la construcción de una ciudadanía secularizada y de una legitimidad política, por la relación directa que se establecía entre la actividad de los ciudadanos y las calificaciones del espacio en que esa dinámica se desarrollaba. El nombre de una calle, sobre todo si se trataba de una vía principal, rodaba continuamente de persona en persona, evocando toda su carga significativa.

La desterritorialización y reterritorialización del espacio público a través del callejero tal vez pudo tener un sesgo laicista para algunos destacados políticos de la izquierda -sobre todo si la nueva toponimia aludía a personajes del panteón histórico español o a símbolos nacionales-, pero fue una clara medida anticlerical para sus bases sociales, ya que el anticlericalismo era su código cultural y político desde el cual interpretar el mundo. Esa misma fue la opinión del cosmos católico. Mutar el nombre, acordar que la madrileña calle del Carmen habría de nominarse de José Nakens -conocido activista furiosamente anticlerical- contenía el significado de descender a la Virgen María de la vida diaria, excretar lo santo, dejar el espacio del día a día vacante de sacralidad, mientras surgía triunfante el nombre de aquellos que más habían abogado por la exclusión pública de la religión. Por ello, durante la Segunda República, la desactivación de la eficacia simbólica del espacio público intentó apuntalar la victoria definitiva de un proyecto de disolución de aquel reino espiritual de Cristo que espacial y temporalmente se encarnaba en las figuras intercambiables de la comunidad social y de la comunidad de fieles. Creemos que el análisis del caso de Madrid resulta ilustrativo de esa política frustrada.

${ }^{63}$ Navarro Navarro, J. 2004. "Movimiento libertario, rituales y símbolos en el espacio público (19311939)", en J. Beramendi y M. X. Baz (Coords.), Memorias e identidades, VII Congreso de la Asociación de Historia Contemporánea: 15. Santiago de Compostela: Universidad de Santiago. Asimismo, Cunill, I. 2010. Los sicarios de la retaguardia (1936-1939). Barcelona: Styra. 


\section{APÉNDICE \\ DESACRALIZACIÓN DEL CALLEJERO MADRILEÑO (1931-1939)}

\begin{tabular}{|c|c|c|c|c|}
\hline Nombre original & Sustituido por & Acuerdo Municipal & Distrito & Barrio/s \\
\hline $\mathrm{C} / \mathrm{del}$ Amor de Dios & Roberto Castrovido & 25.05 .1931 & Centro & Cortes \\
\hline $\mathrm{C} /$ del Amor Hermoso & Mártir Emilio Gudiel & 14.05 .1936 & Usera & Almendrales y Moscardó \\
\hline $\mathrm{C} /$ del Divino Pastor & Javier Bueno & 25.09 .1936 & Centro & Universidad \\
\hline $\begin{array}{c}\text { Plaza de beata María } \\
\text { Ana de Jesús }\end{array}$ & $\begin{array}{c}\text { Francisco Ferrer } \\
\text { Luis Sirval }\end{array}$ & $\begin{array}{l}10.03 .1933 \\
13.06 .1936\end{array}$ & Arganzuela & Chopera y Delicias \\
\hline C/ del Buen Suceso & Mario Roso de Luna & 20.11 .1931 & Moncloa-Aravaca & Argüelles \\
\hline $\begin{array}{c}\text { Plaza de los } \\
\text { Capuchinos de la } \\
\text { Paciencia }\end{array}$ & Rosalía de Castro & 17.05 .1931 & Centro & De la Justicia \\
\hline $\begin{array}{c}\text { C/ del Cardenal } \\
\text { Mendoza }\end{array}$ & Tomás Meabe & 02.11 .1936 & Latina & Puerta del Ángel \\
\hline $\begin{array}{c}\text { C/ de María de los } \\
\text { Ángeles }\end{array}$ & Carlos Rubiera & 14.05 .1936 & Villaverde & Usera \\
\hline $\begin{array}{c}\text { C/ de los Carmelitas } \\
\text { Descalzos }\end{array}$ & Libertad & 25.05 .1931 & Centro & Justicia \\
\hline $\mathrm{C} /$ del Carmen & José Nakens & 24.06 .1931 & Centro & Sol \\
\hline C/ de la Concepción & Igualdad & 07.08 .1931 & Tetuán & Bellas Vistas \\
\hline C/ de la Concepción & Concepción Arenal & 05.07 .1934 & Carabanchel & Vista Alegre \\
\hline $\begin{array}{l}\text { C/ de la Divina } \\
\text { Pastora }\end{array}$ & Don Quijote & 07.08 .1931 & Tetuán & Cuatro Caminos \\
\hline $\begin{array}{l}\text { C/ del Divino } \\
\text { Redentor }\end{array}$ & Catorce de abril & $07.08,1931$ & Castillejos & Carolinas \\
\hline $\begin{array}{l}\text { C/ del Divino } \\
\text { Redentor }\end{array}$ & Catorce de abril & Sin acuerdo municipal & Tetuán & Valdeacederas \\
\hline $\begin{array}{c}\text { C/ de la Huerta del } \\
\text { Obispo }\end{array}$ & Mártires de Chicago & 07.08 .1931 & Tetuán & Berruguete \\
\hline $\mathrm{C} /$ de la Iglesia & Nicolás Salmerón & 19.04 .1931 & Vicálvaro & Casco Histórico \\
\hline $\mathrm{C} /$ de la Iglesia & Pintor Sorolla & 13.04 .1932 & Puente de Vallecas & San Diego \\
\hline $\mathrm{C} /$ de la Iglesia & Cervantes & 19.08 .1931 & Hortaleza & Pinar del Rey \\
\hline $\mathrm{C} /$ de la Iglesia & Juan Bravo & 07.08 .1931 & Chamartín & Barrio de Castilla \\
\hline Glorieta de Iglesia & Pintor Sorolla & 13.04 .1931 & Chamberí & Trafalgar y Almagro \\
\hline Plaza de la Iglesia & González Peña & 03.03 .1936 & Hortaleza & Pinar del Rey \\
\hline Plaza de la Iglesia & Capitán Galán & 21.04 .1931 & Carabanchel & Buenavista \\
\hline $\mathrm{C} / \mathrm{de}$ los Jesuitas & Jaime Vera & 19.04 .1931 & Villaverde & \\
\hline $\mathrm{C} /$ de la Inclusa & Montera & 19.04 .1931 & Centro & Sol \\
\hline $\begin{array}{l}\mathrm{C} / \text { de la Inmaculada } \\
\text { Concepción }\end{array}$ & $\begin{array}{c}\text { Eduardo Ortega y } \\
\text { Gasset }\end{array}$ & 28.04 .1931 & Fuencarral-El Pardo & Valverde \\
\hline $\mathrm{C} /$ de los Jesuitas & Rosario Acuña & 16.03 .1932 & Salamanca & Fuente del Berro \\
\hline Paseo de los Jesuitas & Rosario Acuña & 29.05 .1931 & Salamanca & Fuente del Berro \\
\hline $\begin{array}{l}\text { C/ de la Madre de } \\
\text { Dios }\end{array}$ & Padilla & 07.08 .1931 & Chamartín & Nueva España \\
\hline $\begin{array}{c}\text { C/ de María de los } \\
\text { Ángeles }\end{array}$ & Carlos Rubiera & 14.05 .1936 & Villaverde & Usera \\
\hline $\begin{array}{c}\text { C/ de María del } \\
\text { Carmen }\end{array}$ & España & 21.04 .1933 & Latina & Puerta del Ángel \\
\hline $\mathrm{C} /$ de la Milagrosa & León Tolstoi & 02.10 .1936 & Latina & Puerta del Ángel \\
\hline
\end{tabular}




\begin{tabular}{|c|c|c|c|c|}
\hline Nombre original & Sustituido por & Acuerdo Municipal & Distrito & Barrio/s \\
\hline $\mathrm{C} /$ de la Misericordia & Loreto y Chicote & 04.10 .1933 & Centro & Sol \\
\hline C/ Monte Sinaí & Progreso & 07.08 .1931 & Chamartín & Nueva España \\
\hline $\begin{array}{c}\text { C/ Ntra. Sra. De los } \\
\text { Dolores }\end{array}$ & Conjunción & 07.08 .1931 & Tetuán & Valdeacederas \\
\hline $\begin{array}{l}\text { C/ Ntra. Sra. Del } \\
\text { Carmen }\end{array}$ & Tomás Bretón & 07.08 .1931 & Tetuán & Berruguete \\
\hline $\mathrm{C} /$ del Nuncio & Ricardo Villa & 02.10 .1936 & Centro & Palacio \\
\hline $\mathrm{C} /$ de la Pilarica & Mártires de Octubre & 15.05 .1936 & Usera & Moscardó y Almendrales \\
\hline $\begin{array}{c}\text { C/ de Nuestra Sra. De } \\
\text { las Victorias }\end{array}$ & Proletario & 07.08 .1931 & Tetuán & Cuatro Caminos \\
\hline $\mathrm{C} /$ de Recoletos & Luis Rufilancha & 1936-1939 & Salamanca & Recoletos \\
\hline C/ del Rosario & $\begin{array}{l}\text { Mendoza y } \\
\text { Hernández }\end{array}$ & 13.09 .1936 & Vicálvaro & \\
\hline Plaza del Rosario & Cervantes & 25.03 .1936 & Fuencarral-El Pardo & El Pardo \\
\hline C/ Sacramento & Pablo de Laforque & $02.10-1936$ & Centro & Palacio \\
\hline $\begin{array}{c}\text { Carretera del Sagrado } \\
\text { Corazón }\end{array}$ & De las Artes & 07.08 .1931 & Chamartín & Nueva España \\
\hline $\begin{array}{c}\text { Paseo de los Sagrados } \\
\text { Corazones }\end{array}$ & $\begin{array}{l}\text { Avenida de Galán y } \\
\text { García Hernández }\end{array}$ & 26.04 .1931 & Hortaleza & Hortaleza \\
\hline $\begin{array}{c}\text { Callejuela de San } \\
\text { Andrés }\end{array}$ & Santiago Matteotti & 02.10 .1936 & Centro & Palacio \\
\hline $\mathrm{C} / \mathrm{de}$ San Antonio & Amnistía & 07.08 .1931 & Carolinas & Tetuán \\
\hline $\mathrm{C} /$ de San Antonio & Manuel Llaneza & 18.04 .1934 & San Isidro & Carabanchel \\
\hline $\mathrm{C} / \mathrm{de}$ San Aquilino & Federico Rubio & 07.08 .1931 & Tetuán & Almenara \\
\hline $\mathrm{C} / \mathrm{de}$ San Benito & Ruiz Zorrilla & 07.08 .1931 & Tetuán & Almenara \\
\hline $\mathrm{C} / \mathrm{de}$ San Benito & Noviciado & 07.07 .1931 & Centro & Universidad \\
\hline C/ de San Bernabé & Federico Engels & 02.10 .1936 & Centro & Palacio \\
\hline $\begin{array}{c}\text { Glorieta de San } \\
\text { Bernardo }\end{array}$ & Ruiz Jiménez & 20.07 .1934 & Centro & Chamberí \\
\hline Pasaje de San Blas & República & 29.09 .1932 & Hortaleza & Canillas \\
\hline C/ de San Bruno & $\begin{array}{c}\text { Alcantarilla de la } \\
\text { Cava Baja }\end{array}$ & 02.10 .1936 & Centro & Palacio \\
\hline C/ de San Cristóbal & $\begin{array}{c}\text { Travesía de Mateo } \\
\text { Morral }\end{array}$ & 1936-1939 & Centro & Sol \\
\hline C/ de San Cristóbal & $\begin{array}{c}\text { Gumersindo de } \\
\text { Azcárate }\end{array}$ & 07.08 .1931 & Chamartín & Nueva España \\
\hline $\mathrm{C} /$ de San Eduardo & Carlos Pérez & 13.09 .1936 & Ciudad Lineal & Ventas \\
\hline $\begin{array}{c}\text { C/ de San Francisco el } \\
\text { Grande }\end{array}$ & Juan José Mansó & 14.05 .1936 & Usera & Pradolongo \\
\hline C/ de San Gabriel & Francisco Villaespesa & 02.10 .1936 & Ciudad Lineal & Ventas y Pueblo Nuevo \\
\hline C/de San Gumersindo & Luis Fernández & 19.04 .1931 & Ciudad Lineal & Ventas \\
\hline $\mathrm{C} /$ de San Ildefonso & Roque Barcía & 05.08 .1932 & Centro & Embajadores \\
\hline Avenida de San Isidro & Francisco Ferrer & 10.03.1933 rechazada & Carabanchel & San Isidro \\
\hline C/ de San José & Sargento Vázquez & 19.03 .1936 & Carabanchel & San Isidro \\
\hline C/ de San Joaquín & Ilustración & 07.08 .1931 & Tetuán & Valdeacederas \\
\hline C/ de San José & Pérez Galdós & 07.08 .1931 & Chamartín & Ciudad Jardín \\
\hline C/ de San José & Julián Besteiro & 28.04 .1931 & Fuencarral-El Pardo & \\
\hline C/ de San Juana & Murillo & 07.08 .1931 & Chamartín & \\
\hline C/ de San Leopoldo & Bolívar & 07.08 .1931 & Tetuán & Almenara \\
\hline C/ de San Luis & Carmen de Burgos & 02.10 .1936 & Latina & Puerta del Ángel \\
\hline C/ de San Martín & Milicias Populares & 1936-1939 & Tetuán & Castillejos \\
\hline $\mathrm{C} /$ de San Máximo & Capitán Heredia & 03.06 .1931 & Usera & San Fermín \\
\hline $\mathrm{C} / \mathrm{de}$ San Miguel & Marceliano Isábal & 07.08 .1931 & Tetuán & Berruguete \\
\hline C/ de San Miguel & Dionisio Pérez & 13.09 .1936 & Ciudad Lineal & Quintana \\
\hline
\end{tabular}


Y LOS ESPACIOS PÚBLICOS DURANTE LA SEGUNDA REPÚBLICA

\begin{tabular}{|c|c|c|c|c|}
\hline Nombre original & Sustituido por & Acuerdo Municipal & Distrito & Barrio/s \\
\hline C/ de San Nicolás & Cuatro Vientos & 07.08 .1931 & Chamartín & \\
\hline C/ de San Pablo & Torres Quevedo & 07.08 .1931 & Ciudad Lineal & Costillares \\
\hline $\mathrm{C} /$ de San Pedro & Jaime Vera & 19.04 .1931 & Vicálvaro & Casco Histórico \\
\hline C/ de San Rafael & Agustina de Aragón & 07.08 .1931 & Chamartín & Prosperidad \\
\hline C/ de San Raimundo & $\begin{array}{l}\text { Luis Fernández } \\
\text { Martínez }\end{array}$ & 05.06 .1931 & Tetuán & Bellas Vistas \\
\hline C/ de San Roque & Manuel Llaneza & 07.08 .1931 & Tetuán & Berruguete \\
\hline C/ de San Sebastián & Víctor Hugo & 07.08 .1931 & Chamartín & Castilla \\
\hline $\begin{array}{c}\text { C/ de San Vicente } \\
\text { Mártir }\end{array}$ & Francisco de Goya & 07.08 .1931 & $\begin{array}{c}\text { Chamartín y Ciudad } \\
\text { Lineal }\end{array}$ & \\
\hline C/ de Santa Ana & Máximo Gorki & 02.10 .1936 & Centro & Embajadores \\
\hline C/ de Santa Bárbara & $\begin{array}{l}\text { Emilio Menéndez } \\
\text { Pallarés } \\
\end{array}$ & 08.02 .1932 & Tetuán & Valdeacederas \\
\hline $\mathrm{C} /$ de Santa Casilda & Fernando de Roca & 02.10 .1936 & Arganzuela & Imperial \\
\hline $\mathrm{C} /$ de Santa Catalina & Joaquín Dicenta & 1936-1939 & Centro & Cortes \\
\hline Plaza de Santa Cruz & Liberación & 1936-1939 & Centro & Sol \\
\hline C/ de Santa Eulalia & Villacampa & 07.08 .1931 & Tetuán & Berruguete \\
\hline $\begin{array}{c}\text { Callejón de Santa } \\
\text { Eulalia }\end{array}$ & Villacampa & 07.08 .1931 & Tetuán & Berruguete \\
\hline $\mathrm{C} / \mathrm{de}$ Santa Felisa & Concepción Arenal & 07.08 .1931 & Tetuán & Valdeacederas \\
\hline $\mathrm{C} /$ de Santa Isabel & $\begin{array}{c}\text { María Silva Cruz la } \\
\text { libertaria }\end{array}$ & $1936-1939$ & Centro & Embajadores \\
\hline C/ de Santa Lucía & Jose Duro & 13.09 .1936 & Ciudad Lineal & Costillares \\
\hline C/ de Santa María & Galileo & 07.08 .1931 & Progreso & Valdevivar \\
\hline $\begin{array}{c}\text { C/ Subida a Santa } \\
\text { María }\end{array}$ & Armengot & 18.03 .1932 & Centro & Palacio \\
\hline C/ de Santa Matilde & Castelar & 19.04 .1931 & Ciudad Lineal & Pueblo Nuevo \\
\hline C/ de Santa Mónica & El Greco & 07.08 .1931 & Ciudad Lineal & Colina \\
\hline C/ de Santa Saturnina & Carlos Darwin & 02.10 .1936 & Carabanchel & San Isidro \\
\hline $\mathrm{C} /$ de Santa Sinforosa & Albéniz & 07.08 .1931 & Chamartín & \\
\hline C/ de Santa Teresa & Largo Caballero & 12.07.1931 & Puente de Vallecas & Portazgo \\
\hline C/de Santa Úrsula & José Mesa Llompart & 02.10 .1936 & La Latina & Puerta del Ángel \\
\hline C/de Santa Valentina & Maldonado & 07.08 .1931 & Tetuán & Valdeacederas \\
\hline C/ Santillana & Pablo Iglesias & 28.04 .1931 & Fuencarral-El Pardo & \\
\hline $\mathrm{C} /$ de los Santos & Calatrava & 18.03 .1932 & Centro & Palacio \\
\hline Plaza del Seminario & Enrique de Mesa & 03.07 .1931 & Centro & Palacio \\
\hline $\mathrm{C} /$ de la Victoria & María Guerrero & 11.08 .1933 & Centro & Sol \\
\hline $\begin{array}{l}\text { Paseo Alto de la } \\
\text { Virgen del Puerto }\end{array}$ & Dieciséis de febrero & 24.04 .1936 & Centro y Arganzuela & Palacio e Imperial \\
\hline
\end{tabular}

Elaboración propia. Fuentes: AV, Libros de Acuerdos Municipales del Ayuntamiento de Madrid (vols. desde 1931 a 1937); Aparisi Laporta, L. M. 2001. Toponimia madrileña. Proceso evolutivo I. Nomenclator toponímico. Madrid: Ayuntamiento. 


\section{BIBLIOGRAFÍA}

Alberti J. 2008. La Iglesia en llamas. La persecución religiosa en España durante la Guerra Civil: 439440. Barcelona: Destino.

Álvarez Tardío, M. 2002. Anticlericalismo y libertad de conciencia: Madrid: CEPC

Álvarez Tardío, M. 2011. "La democracia de los radical-socialistas”, F. del Rey(dir.), Palabras como puños. La intransigencia política en la Segunda República Española: Madrid: Tecnos.

Aparisi Laporta, L. M. 2001. Toponimia madrileña. Proceso evolutivo I. Nomenclator toponímico. Madrid: Ayuntamiento.

Arbeloa, V. M. 2008. "Iglesia y Segunda República española”, en Bullón de Mendoza, A. y Togores, L. (Coords.). La República y la Guerra Civil setenta años después: Madrid: Actas.

Arbeloa, V. M. 1973. Socialismo y anticlericalismo: 158-159 y 179-180. Madrid: Siglo XXI.

Argüelles Garrido, J. M. y otros, 1989. "Aportación documental al estudio del callejero madrileño (1860-1967”, Anales del Instituto de Estudios Madrileños III: 451-478.

Calvo Vicente, C. 1993. "Socialización y espacio urbano: el callejero de San Sebastián durante el franquismo". Cuadernos de Sección. Geografia e Historia 21: 345-356.

Cano, L. 2009. Reinaré en España. La mentalidad católica a la llegada de la Segunda República: Madrid: Biblioteca Nueva.

Cantero Muñoz, A. 2005. Historia de la Semana Santa de Doña Mencía (1800-2005): 65. Doña Mencía: Ayuntamiento.

Comas, D., Goñi, J., Pujol, D. 1991. "La revolució i el poder local a la comarca de La Selva a l'estiu de 1936. El cas de Brunyola", Quadern del Cercle d'Estudis Historics i Socials, 7: 223-236.

Costa Vidal, F. 1989. Villena durante la II República. Vida política y elecciones: Alicante: Diputación

Cueva J. de la. 1998."El anticlericalismo en la Segunda República y la Guerra Civil”, E. La Parra y M. Suárez (eds.), El anticlericalismo español contemporáneo: 251 Madrid: Biblioteca Nueva.

Cueva, J. 2007. "Cultura republicana, religión y anticlericalismo: un marco interpretativo para las políticas laicistas de los años treinta" en J. Dronda Martínez y E. Majuelo Gil (eds.). Cuestión religiosa y democracia republicana en España (1931-1939): 55-57. Pamplona: UPN.

Cunill, I. 2010. Los sicarios de la retaguardia (1936-1939). Barcelona: Styra.

Delgado, M. 2007. Sociedades movedizas. Pasos hacia una antropología de las calles: 16. Barcelona: Anthropos.

Delgado Ruiz, M. 1997.“Anticlericalismo, espacio y poder. La destrucción de los rituales católicos, 1931-1939”. Ayer 27: 163-164.

Delgado Ruiz, M. 2001. Luces iconoclastas. Anticlericalismo, espacio y ritual en la España contemporánea: Barcelona: Ariel.

Fernández Morales, M. 2006. Rosario de Acuña, Oviedo: Milenta Muyeres y Ayuntamiento de Gijón

Galán Gamero, J. 1995. Historia de la prensa en Santa Cruz de Tenerife: Tegueste

Gómez Cabornero, S. 2004. "Identidades políticas en la Segunda República: la construcción de los imaginarios colectivos de los vallisoletanos en los años treinta", en J. Beramendi y M. X. Baz 
(Coords.). Memorias e identidades, VII Congreso de la Asociación de Historia Contemporánea. Santiago de Compostela: Universidad de Santiago.

González Orta, J. I. 2010. "Poder local y democracia municipal durante la Segunda República a través de los ayuntamientos: el caso de Villablanca (Huelva)", Historia Actual online 22: 19-31.

González Seoane, M. 2006. "Rosario de Acuña: a masona (1851-1923)". Andaina. Revista do Movemento Feminista Galego, 45: 52-53.

Hernández Figueiredo, J. R. 2009. Destrucción de del patrimonio religioso en la II República (19311936) a la luz de los informes inéditos del Archivo Secreto Vaticano, Madrid: Biblioteca de Autores Cristianos

López Villaverde, Á. L. 2008. El gorro frigio y la mitra frente a frente. Construcción y diversidad territorial del conflicto político-religioso en la España republicana: Barcelona: Ediciones Rubeo

Lalouette, J. 1997. "El anticlericalismo en Francia, 1877-1914”. Ayer 27:15-38.

Luis, M. J. y Sánchez, J. M. 1995. Historia de Santa Cruz de Tenerife. La Laguna: Comunidad Autónoma

Martín Rubio, Á. D. 1997. La persecución religiosa en Extremadura en la Guerra Civil, Badajoz: Autor-Editor.

Martín Rubio, Á. D. 2002. "Educación y formación de una mentalidad anticlerical en España (18751931)", Aportes. Revista de Historia Contemporánea, 49: 74-89.

Miranda, S. 1982. Religión y clero en la gran novela española del siglo XIX: Madrid: Rialp.

Montero Moreno, A. 1961. Historia de la persecución religiosa en España, 1936-1939: Madrid: Biblioteca de Autores Cristianos.

Moral Roncal A.M. 2009. La cuestión religiosa en la Segunda República. Iglesia y carlismo: Madrid: Biblioteca Nueva.

Navarro Navarro, J. 2004. "Movimiento libertario, rituales y símbolos en el espacio público (19311939)", en J. Beramendi y M. X. Baz (Coords.), Memorias e identidades, VII Congreso de la Asociación de Historia Contemporánea: Santiago de Compostela: Universidad de Santiago.

Oliva Escribano, J. L. 1994. "Calles y plazas madrileñas (bibliografía)", Anales del Instituto de Estudios Madrileños XI: 373-390

Pellistrandi, B. 2007. “Clericalismo y anticlericalismo en Francia ¿Una denominación de origen?” en J. de la Cueva y F. Montero (coords.), La secularización conflictiva. España 1898-1931: Madrid: Biblioteca Nueva.

Ramos, M. D. (coord.). 1993. Nuevas perspectivas sobre la Segunda República en Málaga: Málaga: Studia Malacitana-Universidad.

Ruiz-Manjón, O. 1979. "Autoridades locales y partidos políticos en Andalucía durante la Segunda República”, Reis. Revista española de investigaciones sociológicas, 5: 150-171.

Repide, P. de. 1998. Las calles de Madrid. Madrid: Avapiés

Requena, F. M. 2009. Católicos, devociones y sociedad durante la dictadura de Primo de Rivera y la Segunda República: Madrid: Biblioteca Nueva. 
Rubio Pardos, C. 1988. "El uso de patronímicos en los nombres de las calles de Madrid", Anales del Instituto de Estudios Madrileños II: 451-480.

Sainz de Robles, F. C. 1988. "El disparadero disparatero del callejero madrileño", Anales del Instituto de Estudios Madrileños II: 427-445.

Sánchez García-Saúco, J. A. 2001. "La revolución de Asturias: prólogo de la Guerra Civil española” en A. Bullón de Mendoza Y L. Togores (Coords.). Revisión de la Guerra Civil española: 93-111. Madrid: Actas.

Segura González, W. 2008. "La I República y el cantón de Tarifa”, Aljaranda, 71: 17-27.

Velasco Gómez, J. 2008. La Segunda República en Málaga,1931-1936: Málaga: Agora. Centro de Técnicas de Estudio. 